\title{
Analyzing the Cause of Left-Behind Children by Bourdieu's Practical Theory
}

\author{
Yilian Zhang1, Shuangping Chen ${ }^{2 *}$ \\ ${ }^{1}$ School of Humanities, Jinan University, Guangzhou, China \\ ${ }^{2}$ Electrical and Information College, Jinan University, Guangzhou, China \\ Email: zhangyilian26@gmail.com, *afengxx@126.com
}

How to cite this paper: Zhang, Y.L. and Chen, S.P. (2018) Analyzing the Cause of Left-Behind Children by Bourdieu's Practical Theory. American Journal of Industrial and Business Management, 8, 1433-1439. https://doi.org/10.4236/ajibm.2018.86096

Received: May 3, 2018

Accepted: June 5, 2018

Published: June 8, 2018

Copyright (C) 2018 by authors and Scientific Research Publishing Inc. This work is licensed under the Creative Commons Attribution International License (CC BY 4.0). http://creativecommons.org/licenses/by/4.0/

Open Access

\begin{abstract}
At present, the related research on the causes of "left-behind children" is very seldom. Most of literatures are simply summarized as two points: farmers need to survive, and it is the choice of the subject; the second is the inevitable process of China's economic and social development and the objective necessity. In this paper, Bourdieu's Practical Theory, such as Field, capital and habitus three elements, is analyzed and the behavior of workers is explained. It is considered that the phenomenon of left-behind children appearing in large scale in China is not only a problem of economic development, but also a special habitus of "working", which is not simply the individual choice behavior of the parents of left-behind children.
\end{abstract}

\section{Keywords}

Practical Theory, Work Field, Habitus, Left-Behind Children

\section{Introduction}

At all times and in all over the world, parents have the inborn feelings that are indelible to their children, but why are there so many left behind children in China? There is very little literature in China to think deeply about this issue. Generally people simply attributed to some objective external factors such as the needs of migrant workers, household registration system restrictions and so on. Is there no subjective factor for the parents of left-behind children? There is a lot of research on the causes of the formation of left-behind children. There are two main areas: first, they have to work because they are forced to live; second, proceeding from the needs of social structure, it is believed that the emergence of left-behind children is an inevitable process of China's economic and social development. Urbanization needs more migrant workers to work in cities. The 
author thinks that the phenomenon of large-scale left-behind children in rural areas has its specific historical and social reasons as well as the problems of national household registration management. Moreover, it also has certain relations with the present Chinese specific culture. From the perspective of Bourdieu's theory of practice, this paper attempts to consider the causes of the formation of left-behind children from the aspect of social culture. This article is organized in three parts, that is, "field", "capital" and "habitus". It analyzes the Cultural factors which are made from farmers "working" and "habitus" formation, and points out that not only economic problems, but also cultural factors, cause the phenomenon of left-behind children.

The reform and opening up in 1980s has brought great opportunities to China, and China's market economy has been developing vigorously. In the 1990s, the labor boom expanded rapidly, resulting in a large number of children in rural areas being left behind by their parents in rural areas, and parents working in the city. There is no uniform standard for the boundary line or the definition of left-behind children. Academic circles also have some controversy about this. The consensus has been formed: 1) The object involved is the minor whose parents left their hometown for some reason; 2) For various reasons, they cannot go out with their parents to live together; 3 ) To be nurtured or cared for by an acting guardian [1]. The official definition of left-behind children is specifically to rural left-behind children, that is, if the parents or one of the parents is moving from the countryside to the other areas, children stay in rural areas, and so can't live with both parents. Minors aged 17 and below. At present, the number of left-behind children in rural China is huge, which leads to a lot of social problems, so it is particularly important to think about the causes of left-behind children.

\section{Bourdieu's Theory of Practice}

Bourdieu believes that among all the antagonisms that artificially divide the social sciences, the most basic and destructive one is the opposition between subjectivism and objectivism [2]. Author believes that there are many reasons for the phenomenon of left-behind children in rural areas. This paper tries to explain some related reasons from the cultural aspect, and does not consider or involve the economic or political reasons for the time being. This paper analyzes the cultural inducements of left-behind children from the three aspects of field, capital and Habitus through the investigation of rural fields and cases.

\subsection{Social Practice Space: Rural Field}

Bourdieu's "field" refers to the different forms of life, art, science, religion, economy, politics and other space, and gradually forms a unique micro world with their own laws, regulations and authoritative forms. It is a structured space of position, a power field that imposes its own special determinacy on all members who enter it [3]. In practical theory, Bourdieu regards "field" as a network, a 
structure constantly constructed. He believes that each "field" is a unique space, a unique layer, as well as a game with different rules [4]. "Field" is a network organization of relationship, a network society. To think according to the concept of field is to think from the angle of relationship [2]. Bourdieu believes that social space is composed of human action field, social structure is not abstract; social structure can only be carried out symbolically by actors in different fields. It is always closely related to the "survival mentality" of the actors engaged in symbolic practice, and closely related to the various types of social practice carried out by the actors in the struggle and contest of power [5]. At present, there exists the contradiction between reason and emotion in this special field of countryside: as a farmer, you have to work, because if you don't work, you will lose the right to participate in the field of rural discourse, and you will be despised.

Bourdieu said [6]: "the field is not a dead structure, not an empty place, but a game space in which individuals who believe in and pursue the rewards can offer participation in the game." An important feature of the field is that it provides a necessary place for competition, comparison and conversion of all kinds of capital; in turn, the field itself exists and operates. It can only be sustained by the repeated exchange and competition of all kinds of capital [5]. The field under the current rural social space is not only reflected in the implicit symbolic capital competition, but also staged the naked physical space level to represent the position between people. That is, those who have money to buy houses in county towns have moved to the county towns or cities, and those who have no money to buy houses have to stand alone in the increasingly quiet countryside. This physical space, like a razor blade, separates people from high and low household incomes, and it's callous and exposed the different positions to people in the rural field. Therefore, the completely different way of lives, make great pressure to rural residents.

\subsection{Tools of Social Practice: Rural Capital}

Capital exists in the field, only in the relationship with a field, a kind of capital can exist and play a role. There is competition for capital in the field, and capital determines the position of the field and the change of power. The value of capital depends on the existence of the field in which it works. Each field is a place of struggle [7].

Bourdieu divides the competing capital in social space into four categories: economic capital, cultural capital, social capital and symbolic capital (symbol capital).

The economic capital in the traditional countryside has a great relationship with the planting technology. For example whether farmers know how to choose seeds, drought, rain or how to deal with pests and so on. After the 90s, after the start of the labor boom, girls can also go out to work for money. Many families used to have many daughters because they had no sons, and girls worked hard 
and frugally in going out to work, which brought a lot of economic income to families, even more than that of boys. Therefore, the position of people in the rural field has been redistributed; the core is not the number of sons, but the income of family.

Cultural capital. Traditional rural areas actually attach great importance to cultural capital. If ones family member became a college student, and his whole family became very enviable. In rural areas, cadres are often chosen from highly educated people, such as high school graduates, veterans, and so on. The social status and power of individuals or groups in modern society cannot rely solely on the economic capital in their hands, but must also master a large amount of cultural capital [5]. Many parents go out to work, and in fact they want their children to study well and go to college. If their children study well, parents feel that no matter how hard and tired, it is worthy.

Social capital. Social capital is a social resource or wealth that is grasped by a continuous social network [5]. In Chinese traditional villages, interpersonal relations are stable, village cadres are often the representatives of social capital. But that has changed in rural China since the $1990 \mathrm{~s}$. Village cadres are not necessarily the highest social capital in the village, but some in the field of successful workers or entrepreneurs in other areas, they can help introduce fellow villagers to work. This has more material benefit than the social capital of the former village cadres.

Symbolic capital. Symbolic capital, also known as symbol capital, is an important concept used to express symbolic phenomena such as ceremonial activities, reputation or accumulation strategies of prestige capital [5]. The symbolic capital in the rural field is a result of the integration of all capital. For example, villages raise money to build roads at the gate, in the form of equal payments per household and voluntary contributions. Some extremely wealthy families donate a lot of money and their names are engraved on roadside stones. Symbolic capital, no matter what the attribute is, whatever kind of capital, tangible, economic, cultural, social, this attribute is perceived by social actors, their perception categories are so wide that they can feel it, confirm it and make it effective [8].

\subsection{Logic of Social Practice: Working Habitus}

Habitus is a product of the environment or conditions of existence and is mediated by the family in the form of lessons in morality, taboos, worries, rules of behavior and tastes [9]. Habitus refers to a long-term, transferable system of temperament formed by our perception, judgment, and action in the world. It infuses an individual into the foresight of what he wants and what he can get in his relationships [3]. Habitus are the rules for the generation of different and distinctive practices [8]. Bourdieu believes that the activists in the field are not "particles of matter", but people with perceptual, conscious and spiritual attributes [10]. Habitus is an infinite generating ability to generate products completely free-thought, perception, expression, behavior, but these products 
are always limited to the historical and social conditions of Habitus formation [2]. In other words, the acquisition of Habitus is related to the place that people have occupied in this social world for a long time. For example, farmers go out to "work", although the term "working outside" only appeared for decades, but for the present rural youth, "working outside" is undoubtedly a rite of adulthood; For rural parents who have already had children, "working outside" is the way for families to get rich. As the working people at the bottom of China, their economic capital has been at the bottom of the society for a long time, and their cultural capital is also at the bottom of the society. After reform and opening up, the society appears the sharp change, causes the village to have the series chain change. So Bourdieu sees "Habitus" as a socialized subjectivity, as a "collectivization" of biological individuals acquired through socialization. In addition, in Bourdieu's eyes, "habitus" has innate factors but is not entirely innate, it is gradually learned in the socialization of personal circumstances, and gradually evolved "second nature" [4].

\section{Conclusions}

Based on the theory of social practice, practice is a very complicated process. Bourdieu put forward such a formula: (Habitus $\times$ Capital) + Field $=$ Practice [11]. The field is the basis for the existence of habituation, and habituation is the meaning of the existence of the field. Capital determines the formation of habitus, and habitus is the reflection of capital condition and the condition of obtaining capital [7]. In the current rural field, the habitus structure of individual farmers exists in the form of division of labor between men and women, material world, consumption mode, kinship relationship and so on. Driven by consumerism in the mass and minority media, working has become the core of the habitual structure. Not only eating and living need work income to maintain, but even the spiritual world depends on the behavior of working. Farmers in the field, without any other better choice, have to leave their children to work elsewhere. This also coincides with the more rational actions in the field. The more irrational approaches and forms they take, the more the degree of irrationality or even anti-rationalization is implied, and on the contrary, it further strengthens its reasonableness, and makes these rational actions to achieve practical benefits [5].

The comparison of consumption in countryside marriage is becoming more and more serious. Taking the rural areas of Wuhu, Anhui Province, for example, where a man wants to marry a woman, no matter whether he previously lived in a rural area or in a town, the man must at least buy a new house in the town. Moreover, he has to pay for engagement and wedding banquets, and give gifts to the woman's relatives during a few important festivals per year... The average cost of getting married is more than CNY300,000 - 400,000. How can a farmer save so much money? Working in city is the most common way to make money.

In some poor mountain areas, the comparison of building new houses is a 
feature of the field. For example, four left-behind children in Bijie, Guizhou province, committed suicide. Their father spent all his savings on building the house, so after building the house, he continued to go out to work. The author went to Shao Yang, Hunan and other rural areas to research, and also found that the farmers had the psychology of comparing the houses they built. People in the same village compared whose building is taller, whose building is more beautiful and they compared and imitated each other. Villagers go out to earn money and go home to demolish old buildings and build new ones, often at a cost of 100,000 $-300,000$.

On the other hand, "hate to leave a place where one has lived long" is the tradition of Chinese farmers. At present, Chinese farmers" working is only "to work for others temporarily" rather than "working for a long time". That is to say, the peasants always go out to work around their hometown, instead of moving the whole family out of the country. This has something to do with the traditional Chinese thought of "hate to leave a place where one has lived long". Of course, it also has something to do with the gulf between China's urban and rural areas, which is difficult to bridge. Not only is China's tightly managed household registration system, but there are huge differences in the way of life between urban and rural areas, and the cost of family migration is too high for ordinary wage earners to afford. For example, the high housing prices in cities are beyond the reach of many workers. This is a huge difference between Chinese and Western farmers in the process of urbanization. Therefore, the flow of rural and urban areas in China is often just the flow of some workers, workers making money in cities and going back to rural consumption. Just as mainland workers work in Macau, most of them can only live in the mainland.

Farmers put material consumption such as building houses and buying new cars in a relatively heavy position, while they do not treat the health of their children's childhood an important matter. This is an important reason to form the current left-behind children. On the one hand, it is an objective restriction of economic and educational level, and rural residents lack of knowledge about the development of children; On the other hand, the impact of consumerism on rural traditional culture and the great change of rural social values are also part of the reasons. From the perspective of Bourdieu's theory of practice, great changes have taken place in this special field. Some elements in Chinese traditional culture and consumerism are well embedded, which makes consumerism widely spread in China. For example, the combination of face culture and consumerism in traditional Chinese culture makes comparison and vanity more and more popular in the countryside. Under the influence of consumerism culture, the mainstream in the countryside is to measure people's success by money, so making money becomes the primary goal of life. No matter in what channel, as long as one makes more money than others, he will be affirmed and envied by others. And this kind of ability of making money is often shown through consumption. So, for rural residents and some people in the city, consumption is 
not necessarily because of necessity, but mainly because of face consumption.

\section{References}

[1] Liu, Z.J. (2008) On Definition of Left-Home Children and Quantity Estimation. Journal of Guangxi University for Nationalities. Philosophy and Society Edition, 3 , 49-55.

[2] Bourdieu, P. (1980) Le Sens practique. Translated by Zihua Jiang (2003). Yilin Publishing House, Beijing, 37, 84, 133.

[3] Dickinson, 'R., Harindranath, R. and Linne, O. (1998) Approaches to Audience: A Reader. Translated by Bo Shan (2006). Huaxia Publishing House, Beijing, 241.

[4] Liu, Z.Y. (2005) Field, Habitus and Peasants' Fertility Behavior under Bourdieu's Practical Theory. Society, 6, 131-145.

[5] Gao, X.Y. (2004) Pierre Bourdieu's Social Theory. Tongji University Press, Shanghai, 136, 148-151.

[6] Bourdieu, P. and Wacquant, L. (1992) An Invitation to Reflexive Sociology. Translated by Limeng \& Likang (1998). Central Compilation \& Translation Press, Beijing.

[7] Hong, Y.B. and Qi, Y.D. (2014) From Capital to Habitus: The Class Differentiation of Family Educational Pattern in Urban China. Sociological Studies, 4, 73-93.

[8] Bourdieu, P. (1996) Raisons Pratiques. Translated by Lide Tan (2007). SDX Joint Publishing, Beijing, 10, 95-96.

[9] Mander, M.S. (1987). Bourdieu, the Sociology of Culture and Cultural Studies: A Critique. European Journal of Communication, 2, 427-453.

https://doi.org/10.1177/0267323187002004004

[10] Liu, H.G. and Kong, Q.B. (2009) Analysis and Enlightenment of Corruption in the Theory of Field-Habituation. Journal of the Party School of CPC Xiamen Municipal Committee, 1, 56-58.

[11] Zhou, D.X. (2010) Bourdieu's Three Major Concepts: Practice, Habitus, Field. Reform \& Openning, 1, 192-193. 